\title{
Optical Engineering in U.K. Industry
}

\author{
Lionel R. Baker \\ 21 Long Acre \\ Orpington, Kent \\ BR6 7RD, United Kingdom \\ Richard J. Parker \\ Rolls-Royce Applied Science Laboratory \\ P.O. Box 31 \\ Derby \\ DE2 8BJ, United Kingdom
}

More than four and a half years have passed since the first special issue on this subject graced these pages in January 1988. Now, as then, the editors have not attempted to provide a representative or comprehensive survey of the field, but have merely dipped into the rich fountain of activity and expertise in the United Kingdom. What is apparent from both this issue and its predecessor is the sheer diversity of the work: ranging from the latest in sensor technology to the fundamentals of lighting and from definition of new, basic standards to laser vibrometry.

The editors concentrated on papers either from the U.K. industry or from universities working on projects for industry. The reasoning behind this selection was to encourage papers from the usually more reserved industrial researchers, who do not seem to have the same propensity for publication as their academic counterparts.

The differences between this issue and the previous one are also worth noting. In 1988, only two of the papers featured fiber optic technology. In this issue, nearly half of the papers are concerned with applications of optical fibers. This shows the movement of fiber sensors during this period out of the laboratory and into the workplace. This change is also indicative of the confluence of fiber technology and other new, enabling technologies, such as the micromachining of silicon.

Other changes have also been apparent in the U.K. optical community. During this period, the U.K. Optical Engineering Advisory Panel was formed under the auspices of SPIE. This panel has organized, in conjunction with SIRA Ltd., many successful seminars that have sought to bring new developments in optical engineering to the attention of British industry.

Optical engineering still has some way to go in the United Kingdom before being fully recognized for the comprehensive discipline it has become. Several universities now have optoelectronic or optical engineering sections and departments. The research funding bodies, however, have not moved with the times, and would-be researchers in optical engineering must hunt for financial support among the subcommittees of more traditional disciplines, such as physics, electrical engineering, or mechanical engineering.

We hope that the reader will enjoy this selection of papers, and we thank the authors for their efforts. Several additional papers arrived too late for inclusion in this issue and may be published in subsequent issues of the journal. We also take this opportunity to thank the hard-working and unsung referees, without whose instructive and informed criticism the quality of work would not have been maintained.

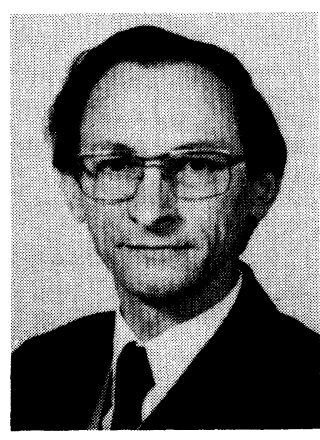

Lionel R. Baker graduated in physics from Imperial College, London, and joined Sira Ltd. in 1958. He was a founding member of the Sira Board of Directors and served from 1972 to 1991. He is named in 45 patent applications including a new method of dynamic stress measurement that resulted in two Queen's Awards for Technology and Exports. The author of 75 technical publications, he lectures regularly to international audiences on the industrial applications of optical technology and technology transfer. In addition to the development of instruments for measuring the optical transfer function, he has recently been responsible for producing a new standard for measuring surface damage. Dr. Baker is currently chairman of the British Standards Institution Committee CPM/17 "Fundamental Standards," convener of CEN.TC123/WG1 "Terminology and Test Methods for Lasers," and a member of ISO/TC172. Dr. Baker is a fellow of the Institute of Physics, SPIE, and OSA. He was executive editor of the Journal of Modern Optics for 17 years. He recently retired as technical director at Sira and now acts as an international consultant and visiting professor of Brunel University, London.

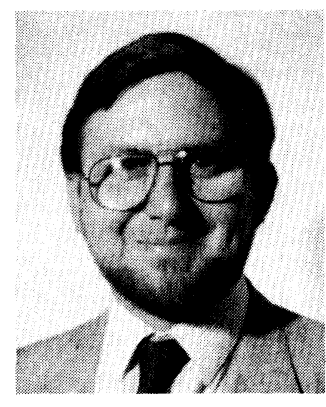

Richard J. Parker earned a BSc degree in physics from Imperial College, London, in 1975. From 1975 to 1978, he worked on an SERC-funded project to study thermoplastic materials for holography. The work was carried out at Imperial College and the National Physical Laboratory. He joined the Advanced Research Laboratory of Rolls-Royce plc., Derby, United Kingdom, in 1978 and in 1986 was appointed group leader of the Optical Sciences Group. The laboratory is now known as the Rolls-Royce Applied Science Laboratory. Parker is responsible for development of laser-based instrumentation. He has published over 20 papers on the subjects of holography and optical diagnostics for aeroengine research. In 1987 he won the International Gas Turbine Institute's JimKamman Awardand in 1991 the Royal Aeronautical Society's Ackroyd Stuart Award. His current research interests include holography, laser Doppler vibrometry, laser anemometry, particle image velocimetry, photomechanics, and nanotechnology. 